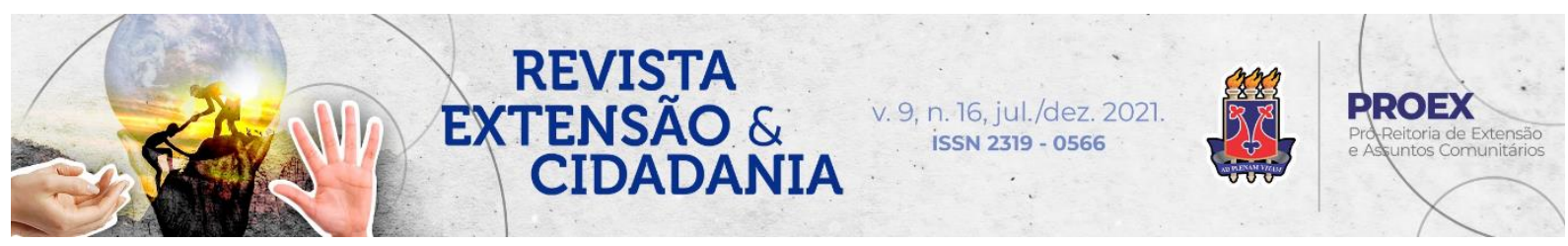

DOI: $10.22481 /$ recuesb.v9i16.8679

\title{
DIAGNÓSTICO E MANIFESTAÇÕES PRECOCES NA ASMA PEDIÁTRICA: O QUE SABEMOS?
}

\author{
DIAGNOSIS AND EARLY MANIFESTATIONS IN PEDIATRIC ASTHMA:WHAT \\ DO WE KNOW?
}

\section{DIAGNÓSTICO Y MANIFESTACIONES TEMPRANAS EN EL ASMA PEDIÁTRICA: QUÉ SABEMOS?}

Flávia Isabelle Barbosa ${ }^{1}$

Sabrina Nayara Pio de Oliveira ${ }^{2}$

Gláucia de Oliveira Moreira ${ }^{3}$

\begin{abstract}
Resumo: Objetivou-se identificar os critérios clínicos utilizados no diagnóstico precoce de asma e as condutas empregadas a fim de otimizar o tratamento. Trata-se de pesquisa de coorte retrospectiva com análise quantitativa dos dados, em amostra estratificada, na qual foram entrevistados pais de pacientes com idades entre 5 e 12 anos, previamente diagnosticados com asma. Dentre as 35 entrevistas analisadas, em 85,7\% havia algum familiar próximo alérgico e em $60 \%$ com asma diagnosticada. Houve discreto predomínio do sexo masculino $(20 / 57,1 \%)$, mas a manifestação de tosse sem sibilância associada, prevaleceu no sexo feminino na relação de 4:1 ( $\left.\square^{2} \mathrm{p}<0,0001\right)$. Os sintomas mais frequentes foram tosse seca $(91,4 \%)$ com piora noturna $(96,8 \%)$, o esforço físico $(84,3 \%)$, o desconforto respiratório $(82,8 \%)$ e o chiado $(85,7 \%)$. Os principais desencadeantes foram: poeira, mofo, fumaça de cigarro, perfume $(94,2 \%)$ e a mudança climática $(88 \%)$. Havia a percepção da melhoracom fenoterol $(65,7 \%)$ e salbutamol $(71,4 \%)$ inalado $\left(p=0,13-\mathrm{X}^{2}\right)$, sendo que os meninos usaram mais $\beta_{2}\left(p=0,03-\mathrm{X}^{2}\right)$ que as meninas. A média e a moda de idade no diagnóstico foram de 2 anos sem diferença entre os sexos. Anti-histamínicos $(80 \%)$ e $\beta_{2}$ de curta ação contínua sem corticoterapia eram comumente usados. A tosse seca, o chiado e o desconforto respiratório recorrentes foram valorizados no diagnóstico, outros fatores considerados foram alergia ou asma familiar, desencadeantes e atenuantes. É imperativa a introdução de ações educativas direcionadas aos profissionais de saúde e pacientes, além da elaboração de estudos adicionais mais amplos.
\end{abstract}

Palavras-chave: Asma. Diagnóstico. Fatores de risco. Saúde da criança. Espirometria.

\footnotetext{
${ }^{1}$ Discente do curso de Medicina, da Universidade Federal de Alfenas (UNIFAL), Alfenas, Minas Gerais, Brasil. Orcid: https://orcid.org/0000-0002-4228-4588 E-mail: flavia.barbosa@ sou.unifal-mg.edu.br

${ }^{2}$ Discente do curso de Medicina, da Universidade Federal de Alfenas (UNIFAL), Alfenas, Minas Gerais, Brasil. Orcid: https://orcid.org/0000-0003-4664-6192 E-mail: sabrina.oliveira@ sou.unifal-mg.edu.br

${ }^{3}$ Pneumologista pediátrica; Doutora $(\mathrm{PhD})$ em Ciências na área de Ensino em Saúde. Docente daUniversidade Federal de Alfenas (UNIFAL-MG), Alfenas, Minas Gerais, Brasil. Orcid: https://orcid.org/0000-0001-7623-8777 E-mail: glaucia.moreira@unifal-mg.edu.br
} 


\begin{abstract}
The aim was to identify the clinical criteria used in the early diagnosis of asthma and the approaches used to optimize the treatment. This is a retrospective cohort study with quantitative data analysis, in a stratified sample, in which parents of patients aged between 5 and 12 years, previously diagnosed with asthma, were interviewed. Among the 35 interviews analyzed, $85.7 \%$ had a close relative who was allergic and $60 \%$ had diagnosed asthma. There was a slight predominance of males (20/57.1\%), but the manifestation of coughing without associated wheezing prevailed in females at a ratio of $4: 1\left(\square^{2} p<0.0001\right)$. The most frequent symptoms were dry cough (91.4\%) with night worsening (96.8\%), physical exertion (84.3\%), respiratory distress (82.8\%) and wheezing (85.7\%). The main triggers were dust, mold, cigarette smoke, perfume (94.2\%) and climate change (88\%). There was a perception of improvement with fenoterol (65.7\%) and salbutamol (71.4\%) inhaled $\left(p=0.13-X^{2}\right)$, with boys using more $\beta_{2}\left(p=0.03-X^{2}\right)$ than girls. The mean and mode of age at diagnosis was 2 years, with no difference between genders. Antihistamines (80\%) and continuous short-acting $\beta_{2}$ without steroids were commonly used. Dry cough, wheezing and recurrent respiratory distress were valued in the diagnosis; other factors considered were familial allergy or asthma, triggering and mitigating. It is imperative to introduce educational actions aimed at health professionals and patients; in addition to the elaboration of additional, broader studies.
\end{abstract}

Keywords: Asthma. Diagnosis. Risk factors infant health. Pulmonary function.

Resumen: El objetivo fue identificar los criterios clínicos utilizados en el diagnóstico precoz del asma y los enfoques utilizados para optimizar el tratamiento. Se trata de un estudio de cohorte retrospectivo con análisis de datos cuantitativos, en una muestra estratificada, en el que se entrevistó a padres de pacientes de entre 5 y 12 años, previamente diagnosticados de asma. De las 35 entrevistas analizadas, el 85,7\% tenía un familiar cercano alérgico y el 60\% habia diagnosticada asma. Hubo un ligero predominio del sexo masculino $(20 / 57,1 \%)$, pero la manifestación de tos sin sibilancias asociadas predominó en el sexo femenino en una proporción de 4: $1\left(\square^{2} p<0,0001\right)$. Los síntomas más frecuentes fueron tos seca $(91,4 \%)$ con empeoramiento nocturno (96,8\%), esfuerzo físico $(84,3 \%)$, dificultad respiratoria $(82,8 \%)$ y sibilancias (85,7\%). Los principales factores desencadenantes fueron el polvo, el moho, el humo del cigarrillo, los perfumes $(94,2 \%)$ y el cambio climático (88\%). Hubo una percepción de mejoría con fenoterol $(65,7 \%)$ y salbutamol $(71,4 \%)$ inhalados $\left(p=0,13-X^{2}\right)$, y los niños utilizaron más $\beta_{2}\left(p=0,03-X^{2}\right)$ que los niños niñas. La edad media y la moda en el momento del diagnóstico fue de 2 años, sin diferencias entre los géneros. Se utilizaron habitualmente antihistamínicos (80\%) y $\beta_{2}$ continuo de acción corta sin esteroides. En el diagnóstico se valoraron tos seca, sibilancias y dificultad respiratoria recurrente; otros factores considerados fueron alergia familiar a asma, desencadenantes y atenuantes. Es imperativo introducir acciones educativas dirigidas a profesionales de la salud y pacientes; además de la elaboración de estudios adicionales más amplios.

Palabras clave: Asma. Diagnóstico. Factores de riesgo. Salud de los niños. Espirometría.

\title{
Introdução
}

A asma é definida como uma doença inflamatória crônica das vias aéreas, que se apresenta por resistência ao fluxo aéreo nas vias condutoras e hiperresponsividade da

Revista Extensão \& Cidadania, v. 9, n. 16, p. 33-51, jul./dez. 2021.

ISSN 2319-0566 DOI: 10.22481/recuesb.v9i16.8679 
musculatura lisa brônquica, à uma variedade de estímulos ambientais. Clinicamente, observamse episódios recorrentes de tosse, sibilos, aperto torácico e dispneia, mais frequentemente no período noturno, pela manhã ao despertar e com esforço físico. É resultante da interação entre herança genética, exposição ambiental a alérgenos ou vírus e compostos irritantes, além de outros fatores específicos que determinam o desenvolvimento e a manutenção dos sintomas (BUSSE; LEMANSKE, 2001; COOKSON, 1999).

Dois diferentes estudos, ao analisarem fragmentos histológicos da mucosa brônquica obtidos endoscopicamente de pacientes com asma branda ou por autópsia de indivíduos asmáticos, observaram: infiltração da mucosa e submucosa com células inflamatórias; descamação irregular do epitélio; espessamento da musculatura lisa da via aérea; fibrose sub epitelial, hiperplasia de glândulas mucosas e de células caliciformes e, também, tampões mucosos disseminados na asma fatal (HOLGATE, 1996; BARNES, 1996). É importante ressaltar que o processo inflamatório crônico pode ocasionar mudanças irreversíveis nas estruturas respiratórias como a intensificação da broncoconstrição e a perda persistente da função pulmonar, que são decorrentes do remodelamento brônquico (MAUAD et al., 2000).

O diagnóstico é fundamentado, principalmente, na anamnese e no exame clínico, sendo complementado, sempre que possível, com os testes de avaliação funcional respiratória e, quando necessário, da avaliação da alergia. Entretanto, na anamnese, a identificação de dados que corroborem com o diagnóstico como a história familiar de asma (STIRBULOV; BERND; SOLÉ, 2006) pode ser indisponível por desconhecimento.

A identificação clínica da asma baseia-se na recorrência dos sintomas respiratórios como a tosse, a sensação de falta de ar, o aperto no peito ou a sibilância e, ainda, na limitação variável do fluxo expiratório demonstrada nas medidas de função pulmonar (GINA, 2018). Quando esses sintomas se associam à piora noturna e ao despertar, melhorando espontaneamente ou após o uso de medicamento específico e surgindo após a exposição a irritantes, fornecem evidências para o diagnóstico de asma (CRUZ et al., 2012).

Em lactentes e pré-escolares, o diagnóstico torna-se mais complexo, já que cerca de $60 \%$ das crianças que sibilam até os três anos de vida não desenvolverão asma (TABACHNIK; LEVISON, 1981; SPORIK; HOLGATE; COGWELL, 1991; MARTINEZ et al., 1995).

Desse modo, por se tratar de uma doença crônica marcada por episódios recorrentes de exacerbação, um dos critérios para o seu diagnóstico é a criança apresentar sintomatologia pelo menos três vezes até o segundo ano de vida, desde que com as características sugestivas citadas

Revista Extensão \& Cidadania, v. 9, n. 16, p. 33-51, jul./dez. 2021. 
previamente (FONTES et al., 2005).

Há alguns critérios de recorrência já identificados como fatores de risco associados à maior chance de desenvolver e/ou persistir com a sibilância recorrente, evoluindo para asma, são eles: história familiar de asma; sexo masculino; início de sintomas na primeira infância; exposição tabágica e a outros poluentes ambientais; história pessoal de rinite alérgica e/ou eczema atópico; valor elevado da Imunoglobulina $\mathrm{E}$ ( $\mathrm{IgE}$ ) total sérica; sensibilização aos alérgenos inalantes e infecções virais associadas à frequência precoce em creches (ex.: vírus sincicial respiratório, rinovírus, influenza) (PINTO; SILVA, 2014). Entretanto, há vários tipos de asma, por isso, esses critérios podem se modificar em função deles, pois a elevação da IgE específica para aeroalérgenos está relacionada ao tipo alérgica ou atópica, com perfil eosinofílico por estimulação da via Th2; enquanto na não alérgica à estimulação da via Th17 resulta em perfil neutrofílico (BELITARDO et al., 2019, p. 87), dificultando a associação dos riscos com o desencadeamento diagnóstico.

A terapêutica deve ser individualizada dentro do espectro de faixa etária e de gravidade de cada caso, o qual deve incluir um plano medicamentoso por escrito, atividades educativas para os pacientes e seus cuidadores, o treinamento para o correto uso e a forma de higienizar o dispositivo inalatório, além de prever a revisão da técnica de uso e o controle sintomático a cada reavaliação (GINA, 2020).

\section{Metodologia}

Foi realizada, após aprovação pelo Comitê de Ética em Pesquisa com Seres Humanos (CEP) explicitado pelo do Projeto sob o Certificado de Apresentação de Apreciação Ética (CAAE) $n^{\circ}$ 13502219.5.0000.5142 e Parecer $n^{\circ}$ 3.567.244, de 11 de setembro de 2019, uma coorte retrospectiva, com amostra aleatorizada e estratificada por conveniência para a obtenção dos dados quantitativos descritos e utilizando-se o teste Qui-quadrado $\left(\square^{2}\right)$ para a análise de dados categóricos. De acordo com a Secretaria Municipal de Saúde (SMS), de Alfenas, Minas Gerais, há 16 Unidades Básicas de Saúde (UBS) no município e, para o presente estudo, foram selecionadas 9 UBS, cada uma representou um grupo de análise. A amostra constituiu-se de pacientes que receberam o diagnóstico de asma nos seus 5 primeiros anos de vida, identificados aleatoriamente por meio dos prontuários médicos, independentemente de estarem em acompanhamento periódico ou não no momento da coleta de dados. Após esta etapa, os Agentes

Revista Extensão \& Cidadania, v. 9, n. 16, p. 33-51, jul./dez. 2021 
Comunitários de Saúde (ACS) eram solicitados a convidar os pacientes e seus responsáveis a comparecerem na UBS a fim de participarem da pesquisa, explicando-lhes os benefícios, os objetivos e a importância do trabalho. Em dia e horário agendados, os voluntários presentes foram novamente orientados pelas estudantes pesquisadoras e os concordantes foram entrevistados por elas, totalizando 35 responsáveis por pacientes de ambos os sexos com idade entre 5 e 12 anos, de acordo com os critérios de inclusão previamente definidos.

Utilizou-se um formulário próprio desenvolvido para a pesquisa, na forma de uma entrevista anônima semiestruturada, respeitando os preceitos éticos previstos pelo CEP. Os sujeitos foram repetidamente informados sobre a confidencialidade e o sigilo das informações coletadas; os prontuários foram utilizados tanto na seleção, quanto como uma ferramenta de apoio para consultar os dados não esclarecidos nas entrevistas. Os dados do questionário foram analisados em uma planilha do Excel com o auxílio de um estatístico da Universidade Federal de Alfenas, Minas Gerais (UNIFAL-MG).

O estudo foi parte integrante das atividades do Projeto de Extensão Universitária registrado na Pró-Reitoria de Extensão da UNIFAL-MG, sob o número 3869, intitulado "Promovendo Saúde: Ações e Interlocuções", no âmbito das ações da Liga de Pediatria da Faculdade de Medicina da UNIFAL-MG, o qual dispõe para o seu desenvolvimento, do termo de parceria firmado com a Coordenação da Atenção Básica da SMS da cidade de Alfenas. Desta forma, o trabalho obedeceu às Resoluções $n^{\circ}$ 466/2012 e no . 580/2018, do Conselho Nacional de Saúde (CNS), do Ministério da Saúde e, aos requisitos exigidos pelo CEP da Universidade.

\section{Resultados}

Das 35 entrevistas, $20(57,1 \%)$ se referiam a pacientes do sexo masculino e 15 $(42,9 \%)$ a do sexo feminino; $20(57,1 \%)$ se declararam brancos; $13(37,1 \%)$ pardos e $2(5,8 \%)$ pretos. A média de renda familiar era de 2 salários-mínimo, com mediana e moda de 1 saláriomínimo.

Dentre os entrevistados, $23(65,7 \%)$ negaram tabagismo no domicílio e $12(34,3 \%)$ confirmaram. Destes que confirmaram, 3 (25\%) somente a mãe; $3(25 \%)$ somente o pai e o restante um outro familiar próximo como irmãos, avós e tios.

Em relação à presença de alergia entre familiares, $30(85,7 \%)$ tinham história positiva. A tosse alérgica foi citada por 8 (26,6\%); bronquite por $15(50 \%)$; alergia alimentar por $3(10 \%)$;

Revista Extensão \& Cidadania, v. 9, n. 16, p. 33-51, jul./dez. 2021. 
rinite alérgica por $19(63,3 \%)$; asma por $21(70 \%)$; dermatite por $3(10 \%)$ e alergia a medicamentos por $2(6,6 \%)$.

Em 18 crianças $(51,4 \%)$, o diagnóstico de asma foi informado nos primeiros 2 anos de vida (média e moda de 2 anos), a idade mínima foi inferior a 2 meses. A maioria iniciou o tratamento aos 2 anos de idade (DP 2,4); uma criança usava broncodilatador de curta ação desde o nascimento, concomitantemente $8(22,8 \%)$ relataram diagnóstico de refluxo gastroesofágico e $21(60 \%)$ delas recebeu pelo menos uma vez o diagnóstico de pneumonia quando buscaram atendimento durante as exacerbações.

A tosse seca foi referida por $32(91,4 \%)$, com piora noturna em $31(96,8 \%)$ e, associada a esforços físicos em 27 (84,3\%), tendo havido recorrência dos sintomas pelo menos três vezes em $34(97,1 \%)$ pacientes até o diagnóstico. O chiado foi relatado por $30(85,7 \%)$ e o desconforto respiratório por $29(82,8 \%)$ respondentes. O relato de tosse não associada à sibilância ou ao chiado ocorreu com maior frequência no sexo feminino, em uma relação de 4:1 ( $\square^{2} p<0,0001$ ). O diagnóstico concomitante de rinite alérgica apareceu em 5 (14,2\%) pacientes.

Dentre os fatores de piora, a exposição à poeira, ao mofo, à fumaça de cigarro e ao perfume foram referidos por $33(94,2 \%)$ entrevistados e a mudança climática por 31 (88\%), principalmente nos meses de inverno em 7 (36,8\%), na primavera em 2 (10,5\%), no outono em outros $2(10,5 \%)$ e no verão para $1(5,2 \%)$, notadamente no período noturno em 30 (85,7\%).

Dos medicamentos referidos, $32(91,4 \%)$ utilizaram os broncodilatadores de curta ação, sendo o salbutamol citado por 27 (84,3\%). Essa medicação era utilizada exclusivamente nas agudizações por $26(81,2 \%)$ crianças. Em $6(17,1 \%)$, com uso medicamentoso contínuo ou diário; 3(50\%) relataram uso de salbutamol sem corticoterapia. Das crianças do sexo masculino, $20(100 \%)$ utilizavam o broncodilatador de curta ação, enquanto no sexo feminino $12(80 \%)$ se referiram ao uso ( $\left.\square^{2} p=0,03\right)$. Para uma criança (2,8\%), citou-se o uso de Acebrofilina; para 29 $(82,8 \%)$ o anti-histamínico, predominando a loratadina $(82,7 \%)$. A percepção de melhora associada ao uso do fenoterol ocorreu em $65,7 \%$ e do salbutamol em 71,4\% ( $\left.\square^{2} p=0,13\right)$.

O uso do corticoide oral foi referido por $24(68,5 \%)$ dos entrevistados, representado principalmente pela prednisolona $(62,5 \%) ; 2$ (8,33\%), citaram o dipropionato de beclometasona; $1(4,1 \%)$ a associação de salmeterol e propionato de fluticasona; $2(8,2 \%)$ associação de formoterol com budesonida, sendo todos nas crises.

Dos 8 pacientes que receberam oxigenoterapia em algum quadro agudo, 3 (37,5\%) mencionaram o uso de corticoide inalado e $1(2,8 \%)$ tinha histórico prévio de 4 internações por

Revista Extensão \& Cidadania, v. 9, n. 16, p. 33-51, jul./dez. 2021. 
asma, referindo usar salbutamol associado à loratadina nas crises mais graves, negando uso prévio de corticoide sistêmico ou inalado no domicílio. Dos 5 respondentes que mencionaram sintomas diários, 2 usavam corticoterapia inalada.

Em 26 crianças $(74,2 \%)$, foram referidos à utilização de medicação inalatória com espaçador, avaliando-se a técnica, em 22 (84,6\%), houve o relato adequado; quanto à frequência, $16(61,5 \%)$ usavam 1 ou 2 vezes ao dia e, na maioria, a medicação era o salbutamol, sendo que $9(36 \%)$ disseram não perceber melhora.

Dos 32 pacientes que citaram ter tomado antibiótico durante uma exacerbação, 15 $(46,8 \%)$ relataram ter recebido o diagnóstico médico de pneumonia associada, os demais mencionaram terem sido para Infecção do Trato Urinário, Infecção das Vias Aéreas Superiores (sinusite, faringite, otite), peito cheio, tosse, alergia e crises de asma.

\section{Discussão}

A discreta predominância masculina da amostra é condizente com a literatura, a qual associa aos meninos uma constituição pulmonar mais favorável ao aparecimento das doenças obstrutivas como a asma, estando associados a uma menor função pulmonar e maior sensibilidade aos aeroalérgenos (REIS, 1997; CRUZ et al., 2012; SOUSA et al., 2012). Essa diferença de prevalência entre os sexos masculino e feminino deve desaparecer na puberdade, quando os meninos passam a apresentar um maior desenvolvimento da caixa torácica e, consequentemente, a razão diâmetro/comprimento da via aérea se iguala entre meninos e meninas (SOLÉ et al., 1998).

Vários estudos encontraram uma maior prevalência de asma em crianças de pele preta ou parda, devido às diferenças biológicas e aos processos discriminatórios que determinam um menor acesso aos recursos e aos serviços de saúde (CHATKIN et al., 2003; CHATKIN; MENEZES, 2005). A predominância, neste estudo, de autodeclarados brancos em amostra originária, principalmente de pacientes atendidos nas UBS mais centrais do município, configura um fator de confusão, além da autodeclaração ser subjetiva e baseada em aspectos culturais, podem subestimar o número de crianças de pele preta e parda.

A exposição à fumaça do cigarro parece se associar a maior gravidade e morbidade da asma na infância, por acelerar a perda da função pulmonar, ao aumentar a inflamação das pequenas vias aéreas mediada por neutrófilos e macrófagos e potencializar a hiperresponsividade brônquica,

Revista Extensão \& Cidadania, v. 9, n. 16, p. 33-51, jul./dez. 2021. 
obstruindo o fluxo aéreo e diminuindo a qualidade de vida do paciente (VIEGAS, 2009; LANG; TANG, 2019). Os pais das crianças submetidas ao ambiente tabágico verbalizaram crises mais graves e intensas com maior dificuldade de controle. Apesar de a relação do tabagismo passivo no desenvolvimento da asma como uma associação direta ser difícil de determinar (ULRIK et al., 1996; LEWIS et al., 1996), o estudo retrospectivo observacional conduzido por Collet et al. (2021) identificou uma relação dose-efeito para o tabagismo materno durante a gestação, repercutindo no maior tempo de internação de lactentes com quadro de sibilância, não necessariamente asma, contudo, a história de tabagismo gestacional não foi coletada na presente análise. Nesta pesquisa, 23 (66\%) asmáticos não conviviam com tabagistas, no entanto, estudos adicionais com maior tamanho amostral são necessários para se avaliar a possível associação com a gravidade dos sintomas e o diagnóstico de asma.

A alta prevalência de alergia familiar associada ao diagnóstico de asma encontra justificativa na predisposição genética relacionada à exposição ambiental aos alérgenos ou aos compostos irritantes (COOKSON, 1999; BUSSE; LEMANSKE, 2001). Alguns autores demonstram, em estudos com gêmeos, a influência genética na manifestação da asma, estimando sua hereditariedade, ao sugerir que alguns cromossomos possuem genes capazes de regular os níveis séricos de Imunoglobulina E ou mesmo promover a mudança do isótipo IgE. Este, em níveis elevados, se associa fortemente às manifestações de atopia e à asma na infância, influenciando na gravidade e persistência sintomatológica após os 3 anos de idade (PINTO; STEIN; KABESCH, 2008; PINTO; STEIN; RIBEIRO, 2009). Neste estudo, a grande maioria dos pacientes não apresentava tal dosagem, o que pode ser devido às dificuldades para sua realização no âmbito do Sistema Único de Saúde (SUS) local, tornando não possível o aprofundamento nessa análise, considerando-se somente o relato dos entrevistados.

Há referências quanto à possibilidade da Doença do Refluxo Gastroesofágico (DRGE) desencadear os sintomas asmáticos, a partir da verificação de que o contato do $\mathrm{pH}$ ácido gástrico com o esôfago distal acarrete o reflexo de broncoconstrição, reduzindo a função pulmonar. Em contrapartida, a asma também induziria os episódios de RGE devido ao aumento do esforço respiratório (aumento da pressão intra-abdominal) com o surgimento da DRGE (KUWAKINO et al., 2007; MARTINS, 2007). Apesar de ser uma relação controversa, outros autores demonstraram uma maior prevalência da DRGE em crianças asmáticas, com maior ocorrência associada aos casos moderados e graves, os quais persistem sintomáticos por períodos mais longos e com agravamento noturno devido ao decúbito (TEIXEIRA et al., 2007; TEBET, 2000).

Revista Extensão \& Cidadania, v. 9, n. 16, p. 33-51, jul./dez. 2021. 
Nos estudos sem a classificação pela gravidade da asma, a prevalência da DRGE seria significativamente menor (KUWAKINO et al., 2007; SHEIKH et al., 1999), podendo justificar o observado no presente estudo, uma vez que a categorização dos pacientes pela gravidade não foi possível devido ao pequeno tamanho amostral, e onde identificou-se 8 (22,8\%) crianças com diagnóstico concomitante de DRGE. Entretanto, chama a atenção que $23(65,7 \%)$ relacionaram à piora dos sintomas asmáticos com o decúbito dorsale $9(25,7 \%)$ com a alimentação, mas os 8 $(22,8 \%)$ diagnosticados com DRGE não estão entre eles, podendo sugerir a necessidade de uma investigação adicional para que se avalie a possibilidade da DRGE entre eles.

Apesar da literatura ser concordante quanto à dificuldade em se diagnosticar asma nos menores de 5 anos de idade, neste levantamento, o diagnóstico foi na maioria dos casos $(51,4 \%)$ efetuado nos primeiros dois anos de vida, consequentemente, a quase totalidade (94,3\%) já tinha o diagnóstico antes de completar cinco anos, sendo a faixa etária em que o diagnóstico demanda maior embasamento em aspectos clínicos, devido às limitações existentes para se executar a confirmação por medidas objetivas de função pulmonar (CRUZ et al., 2012).

Levando-se em conta que os sintomas clínicos da asma são variáveis e inespecíficos, que muitas crianças que sibilam até os dois anos de idade não manifestarão asma e, considerando que cerca de $40 \%$ delas irão sibilar ao menos uma vez nos três primeiros anos de vida, é preciso excluir outras causas, principalmente para os que iniciam os sintomas nos primeiros meses de vida (TABACHNIK; LEVISON, 1981; SPORIK; HOLGATE; COGWELL, 1991; MARTINEZ et al., 1995; PEDERSEN et al., 2011). Entretanto, como aproximadamente $50 \%$ a $80 \%$ das crianças com asma manifestam clinicamente a doença durante os primeiros anos de vida (CAMELO-NUNES; SOLÉ; NASPITZ, 1997; FONTES et $a l ., 2005)$ e analisando a persistência dos sintomas acima dos três anos de idade, seria importante neste momento se proceder à avaliação da atopia para os casos pertinentes, da DRGE para os casos suspeitos, da função pulmonar para todos que consigam executar a manobra para a medida do pico de fluxo expiratório (PFE) e para a espirometria (prova completa) com o estadiamento da gravidade e do nível de controle da asma. Até porque, durante as agudizações, principalmente nos atendimentos de urgência e emergência, o PFE é parte integrante da avaliação da gravidade do quadro de exacerbação e da resposta à terapêutica (GINA, 2021).

Para o diagnóstico de asma é indicado avaliar os sintomas, suas características e periodicidade, associadas à recorrência e não restritos aos relacionados aos quadros virais (PIZZICHINI et al., 2020; FIKS, 2008). As manifestações refletem a inflamação crônica das

Revista Extensão \& Cidadania, v. 9, n. 16, p. 33-51, jul./dez. 2021. 
vias aéreas inferiores, desencadeando uma contração rápida frente a uma ampla gama de estímulos, configurando a hiperresponsividade (CAMPOS, 2007).

Observa-se no grupo estudado, um quadro clínico compatível com sintomas em caráter recorrente e com as características esperadas, sugerindo o provável diagnóstico de asma. Quanto ao tratamento referido, também é utilizado na avaliação diagnóstica, a melhora ou a constatação da reversibilidade da obstrução após o uso das medicações de alívio, no caso os broncodilatadores e, uma vez que o salbutamol é um broncodilatador de curta duração, sabe-se que deve ser utilizado a cada 4 horas. Portanto, a falta de resposta relatada em alguns casos pode ser decorrente do excessivo distanciamento entre as doses, contudo, nos pacientes que se referem aos sintomas, desde o nascimento ou nos primeiros 2 meses de vida, é necessária uma cuidadosa revisão quanto à possibilidade de diagnósticos alternativos.

As mudanças climáticas, exercícios físicos, exposição aos produtos de limpeza, à poeira, ao mofo, à fumaça de cigarro e ao perfume são os chamados gatilhos, sendo reconhecidos na literatura, como potenciais desencadeantes de quadros de exacerbação asmática (TRINCA; BICUDO; PELICIONI, 2011). Os desencadeantes podem ser considerados como irritantes ou alérgenos, que deflagram a hiperresponsividade das vias aéreas inferiores, desencadeando uma obstrução parcial e reversível ao fluxo aéreo. Há relatos de uma piora em $78 \%$ dos casos expostos à poeira e em $88 \%$ dos submetidos à mudança climática (ALVES; VIANNA; PEREIRA, 2008). Da mesma forma que foi relatado nesta pesquisa (FERNANDES et al., 2017), a piora na primavera pode sugerir a alergia a pólens que induzem a inflamação dos brônquios, outro gatilho deflagrador para quem for sensibilizado.

A piora da tosse seca à noite e com o esforço físico pode se relacionar à queda do fluxo expiratório esperada nesse período, havendo uma maior contração do calibre brônquico durante a madrugada e maior resistência das vias aéreas, o que se relaciona à ausência do controle da doença (ARAÚJO et al., 2014). A piora com o esforço pode caracterizar o broncoespasmo induzido pelo exercício (BIE), descrito como consequente ao aumento transitório da resistência das vias aéreas após atividade enérgica, podendo estar presente em 80 a $90 \%$ das crianças portadoras de asma (FIKS, 2008; TENROLLER, 2004).

Para o tratamento inicial, é necessário identificar a gravidade do quadro, considerandose a frequência e a intensidade dos sintomas, as medidas objetivas da função pulmonar e a resposta ao tratamento, entretanto, para o tratamento de manutenção, deve-se associar aos critérios de controle (STIRBULOV; BERND; SOLÉ, 2006). Após a classificação, a criança se

Revista Extensão \& Cidadania, v. 9, n. 16, p. 33-51, jul./dez. 2021. 
encaixa em uma etapa do tratamento, em que será indicada a melhor forma de manejo da medicação (GINA, 2020). Os broncodilatadores ( $\beta 2$ agonistas) são utilizados no alívio ou resgate nas exacerbações, sendo utilizados em todas as etapas do manejo da asma, logo, é esperado que todos os pacientes usem em algum momento, como recomendado nos protocolos, os quais utilizam sua frequência de uso como parte da avaliação do controle obtido (FERREIRA et al., 2019). O salbutamol foi usado por 27 (84\%) dos entrevistados, corroborando com o indicado na literatura (BRASIL, 2010).

Os broncodilatadores são medicamentos de alívio que não atuam na inflamação, estando os corticoides indicados para o controle da doença, de acordo com a idade e a gravidade (GINA, 2020). Observou-se um número expressivo de crianças, cujos cuidadores referiram ter usado corticoide (68,5\%), prevalecendo a Prednisolona (62,5\%) a qual juntamente com a Prednisona são as drogas mais administradas no tratamento da asma infantil, devido ao seu custo-benefício e à meia-vida intermediária, expondo ao menor risco de efeitos colaterais, com absorção rápida e completa pelo trato gastrointestinal em comparação com outras (SANTANA; MENNA BARRETO; CARVALHO, 1997). Nos estudos mais recentes, há uma progressiva preferência pelo uso de sua apresentação inalada, reduzindo exponencialmente a dosagem administrada e restringindo ao uso da formulação oral para os casos de maior gravidade (GINA, 2021). Uma fragilidade deste estudo se deve ao fato de não se ter detalhado mais sobre o uso dessas formulações, por exemplo, analisando-se quanto ao uso não prescrito do corticoide oral ou do não respeito ao uso contínuo por um período determinado das formulações inalatórias para o controle, uma vez que se identificou considerável insegurança dos cuidadores em relação ao diagnóstico, à evolução da doença, suas associações e estratégias terapêuticas utilizadas.

Outras fragilidades detectadas foram o reduzido tamanho amostral, o qual foi imposto pela eclosão da pandemia da Covid-19, determinando a interrupção precoce da coleta dos dados impedindo sua continuidade. Apesar disto, as estudantes do curso de graduação médica puderam compartilhar com os pais das crianças envolvidas e com a equipe de saúde das UBS uma importante experiência reflexiva quanto às dificuldades de comunicação, ao fluxo de funcionamento do SUS e, sobretudo, quanto à carência manifestada pelos usuários, de tempo suficiente durante os atendimentos para sanar suas dúvidas e trocar experiências em relação ao quadro de saúde de seus descendentes. Apesar de se crer na adequada orientação prestada aos pacientes, ficou evidente a necessidade de ser implantado um sistema educativo especialmente voltado aos pacientes crônicos e aos seus cuidadores.

Revista Extensão \& Cidadania, v. 9, n. 16, p. 33-51, jul./dez. 2021. 
Os dados analisados indicaram, ainda, a possibilidade de um uso excessivo de medicamentos não indicados no tratamento da asma, como os anti-histamínicos e antibióticos, e uma utilização aquém da ideal para os broncodilatadores e corticoides inalados, necessitando de um aprofundamento das pesquisas e das estratégias de atualização dos profissionais de saúde que atuam na rede. Sendo ainda, necessário identificar acerca dos mitos culturais que possam influenciar as condutas aplicadas e recebidas.

Nesse sentido, alguns pontos cruciais podem ser elencados: a ausência no uso da medicação de resgate por algumas crianças; o uso isolado e frequente do salbutamol; a ausência do uso do PFE pelos profissionais da rede tanto hospitalar quanto ambulatorial; a deficiência na solicitação de espirometria, de investigação da alergia e dos diagnósticos diferenciais em alguns casos; a falta de uso do corticoide inalado preventivo, principalmente naqueles com asma não controlada e nos que manifestaram quadros de maior gravidade, casos em que a literatura recomenda formalmente o uso do corticoide inalatório (GINA, 2020; GINA, 2021; PIZZICHINI et al., 2020) como medida de importância pelo efeito anti-inflamatório, capaz de prevenir o remodelamento das vias aéreas e a evolução para a obstrução irreversível, sendo que a baixa taxa de uso pode ser associada à falta de adesão ao tratamento e à escassez de conhecimento acerca da fisiopatologia da doença (FONTES et al., 2005).

Pode-se pontuar ainda o uso da metilxantina e do fenoterol por alguns pacientes, medicações que, por questões de segurança, não são comumente indicadas, as da primeira classe somente estão indicadas em casos graves refratários a outras terapias, como ocorre em pacientes admitidos em unidades de terapia intensiva (UTI); já o fenoterol, deve ser preterido em relação ao salbutamol, uma vez que ambos são broncodilatadores de curta ação (pertencem a mesma classe), devido a se ter verificado em estudos na década de 1990, um maior risco de ectopias cardíacas e de morte entre seus usuários, sem haver benefícios para a função pulmonar em relação às doses equivalentes de salbutamol, o qual pode ser explicado pela seletividade 10 vezes maior para os receptores $ß 2$, deste último, implicando em menor efeito indesejável sobre os receptores B1 (BREMNER et al., 1992; SUISSA et al., 1994; SCALABRIN et al., 1996; EMERYK; EMERYK-MAKYMIUK, 2020). Destaca-se que o salbutamol em inalador dosimetrado se encontra amplamente disponível a custo zero no Brasil, pelo Programa da Farmácia Popular do Governo Federal.

Outro fármaco, incluído no referido Programa, é o corticoide inalado, dipropionato de beclometasona, também amplamente disponível a custo zero para o tratamento de manutenção

Revista Extensão \& Cidadania, v. 9, n. 16, p. 33-51, jul./dez. 2021. 
dos pacientes asmáticos, representando uma boa relação custo/benefício para o tratamento antiinflamatório e, o consequente controle sintomatológico da doença, possibilitando a redução considerável na recorrência dos sintomas, no risco de ocorrência de uma exacerbação grave, possivelmente fatal e, consequentemente, na frequência de idas aos serviços de emergência e de hospitalizações (MOURA; CAMARGOS; BLIC, 2002; STIRBULOV; BERND; SOLÉ, 2006; GINA 2018; GINA, 2020; PIZZICHINI et al., 2020).

Destaca-se a constatação positiva de que a maioria dos usuários das formulações em spray dosimetrado descreveu a realização da técnica correta, o que pode ser atribuído à escolha adequada do dispositivo quanto ao custo/benefício; à preferência do paciente; à facilidade de transporte; à efetividade da droga administrada; à orientação e treinamento adequados do paciente e seus cuidadores pela equipe de saúde, além do uso de apenas um tipo de dispositivo, e à avaliação periódica, citados como fatores que podem estar relacionados ao sucesso (STIRBULOV; BERND; SOLÉ, 2006).

O uso de antibióticos foi quase universal, tendo sido prescrito na maioria dos casos $(91,4 \%)$ com o intuito de tratar sintomas de tosse seca, desconforto respiratório e sibilância, de acordo com os relatos dos cuidadores, o que não encontra respaldo na literatura especializada, mas que encontra eco nos autores que identificaram o uso indiscriminado de antibióticos em portadores de asma, devido à dificuldade em se distinguir ou excluir as infecções bacterianas do trato respiratório, mesmo sabendo-se que a maioria das infecções pediátricas associadas às exacerbações são de etiologia viral, merecendo atenção à forte associação entre o uso de antibióticos precocemente (no primeiro ano de vida) e ao desenvolvimento posterior de asma, o que foi relatado por autores que observaram a influência negativa desses fármacos sobre a flora intestinal, destruindo as bactérias benéficas que desempenham importante papel para o desenvolvimento do sistema imunológico, gerando prejuízos imunitários, que podem aumentar a susceptibilidade às doenças alérgicas (RISNES et al., 2011; BRICKS, 2003; NASCIMENTO-CARVALHO, 2006; MORAES et al., 2013).

Não há indicação para o uso de antibioticoterapia nas exacerbações de asma, a qual pode ser considerada, caso haja alguma evidência de coinfecção bacteriana, ou nos casos severos com perda de parâmetros discriminatórios evidentes, nos quais medidas invasivas de tratamento em regime de hospitalização sejam necessárias (ASENSI MONZÓ, 2017). Por isso, alguns autores dedicaram pesquisas específicas à prescrição excessiva de antibióticos nas manifestações de asma (CHONG-NETO et al., 2020; RIBEIRO et al., 2013; ANDRADE et al.,

Revista Extensão \& Cidadania, v. 9, n. 16, p. 33-51, jul./dez. 2021. 
2015; ANIBARRO PEREZ; ALONSO CLAVERO; DEL NIDO ALONSO, 2009). Neste estudo, a principal justificativa para sua prescrição foi o diagnóstico adicional de pneumonia, seguida de faringite aguda, sinusite aguda e otite média aguda. Não esquecendo-se de que a pneumonia é uma das complicações mais comuns em pacientes com quadros asmáticos de maior gravidade (SANTANA; MENNA BARRETO; CARVALHO, 1997). Embora infrequente essa associação e, estando mais restrita aos casos severos, a pneumonia constitui relevante causa de mortalidade pediátrica, principalmente nos primeiros cinco anos de idade (NASCIMENTO-CARVALHO, 2006).

\section{Considerações finais}

Na impressão dos cuidadores ou responsáveis, a tosse seca, o chiado e o desconforto respiratório foram os principais sintomas recorrentes valorizados no diagnóstico, além da genética familiar, dos desencadeantes ambientais e dos fatores atenuantes. A manifestação de tosse não associada à sibilância evidente, mais relatada no sexo feminino e a maior frequência de uso de broncodilatadores pelo sexo masculino, pode sinalizar para uma maior proporção de tosse como variante de asma e de casos mais brandos entre as meninas. Entretanto, a maior contribuição deste estudo foi trazer a percepção de que ainda existe uma falta de entendimento por parte do paciente, dos seus familiares e cuidadores, e até do próprio profissional de saúde, quanto à gravidade, à cronicidade, às implicações futuras e ao acompanhamento ou tratamento mais adequado aos pacientes portadores de asma, o que compromete o controle da doença e impõem riscos adicionais.

Por fim, apesar de serem necessários novos e mais amplos estudos nesta área, é indiscutível a necessidade de se desenvolver atividades educativas envolvendo o estudante de medicina, as equipes de saúde dos serviços nos diferentes níveis de atenção, gestores destes sistemas e, principalmente, a comunidade assistida, aproximando a academia da população, para que, através da maior interlocução entre todos os componentes da rede, possa haver a construção coletiva das estratégias que atenda realmente às necessidades dos pacientes crônicos e aos seus cuidadores.

Revista Extensão \& Cidadania, v. 9, n. 16, p. 33-51, jul./dez. 2021. 


\section{Referências}

ALVES, R. S. A.; VIANNA, F. A. F.; PEREIRA, C. A. C. Fenótipos clínicos de asma grave. Jornal Brasileiro de Pneumologia, v. 34, n. 9, p. 646-653, 2008.

ANDRADE, J. M. A. et al. Perfil da utilização de antibióticos em crianças internadas num hospital infantil no interior do estado do Ceará. Boletim Informativo Geum, Teresina, v. 6, n. 3, p. 15-21, jul./set. 2015.

ANIBARRO PEREZ, S.; ALONSO CLAVERO, A.; DEL NIDO ALONSO, M. Programa del asma en Atención Primaria: estudio comparativo entre dos centros de salud de Valladolid.

Revista Pediatría de Atención Primaria, Madrid, v. 11, n. 42, p. 241-249, 2009.

ARAÚJO, D. L. et al. Avaliação da qualidade do sono e da qualidade de vida na asma. Journal of Allergy and Clinical Immunology, v. 2, n. 3, p. 107-111, maio/jun. 2014.

ASENSI MONZÓ, M. Crisis de asma. Revista Pediatría de Atención Primaria, Madrid, v. 26, Supl., p. 17-25, 2017.

BARNES, P. J. Neuroeffector mechanisms: the interface between inflammation andneuronal responses. Journal of Allergy and Clinical Immunology, v. 98, n. 5, p.73-81, 1996.

BELITARDO, E. M. M. A. et al. Receptores toll like (TLR) e a resposta imune na atopia e na asma brônquica. In: COSTA, S. L.(org.). Avanços da pesquisa em imunologia na Bahia: 30 anos de contribuição do Programa de Pós-Graduação em Imunologia da UFBA. Salvador: Ed. da UFBA, 2019. p. 87.

BRASIL. Ministério da Saúde. Secretaria de Ciência, Tecnologia e Insumos Estratégicos. Departamento de Assistência Farmacêutica e Insumos Estratégicos. Formulário Terapêutico Nacional 2010. 2. ed. Brasília, DF: Ministério da Saúde, 2010.

BREMNER, P. et al. Nebulized fenoterol causes greater cardiovascular and hypokalaemic effects than equivalent bronchodilator doses of salbutamol in asthmatics. Respiratory Medicine, v. 86, n. 5, p. 419-423, 1992.

BRICKS, L. F. Uso judicioso de medicamentos em crianças. Jornal de Pediatria, Rio de Janeiro; PortoAlegre, v. 79, n. 1, supl., p. 107-114, jun. 2003.

BUSSE, W. W.; LEMANSKE, R. F. Asthma. New England Journal of Medicine, v. 344, n. 5, p. 350-362, Feb. 2001.

CAMELO-NUNES, I. C.; SOLÉ, D.; NASPITZ, C. K. Fatores de risco e evolução clínica da asma em crianças. Jornal de Pediatria, Rio de Janeiro, v. 73, n. 3, p. 151-60, 1997.

CAMPOS, H. S. Asma: suas origens, seus mecanismos inflamatórios e o papel do corticosteroide. Revista Brasileira de Pneumologia Sanitária, v. 15, n. 1, p. 47-60, dez. 2007.

Revista Extensão \& Cidadania, v. 9, n. 16, p. 33-51, jul./dez. 2021. 
CHATKIN, M. et al. High prevalence of asthma in preschool children in SouthernBrazil: a population-based study. Pediatric Pulmonology, v. 35, n. 4, p. 296-301, 2003.

CHATKIN, M.; MENEZES, A. M. Prevalence and risk factors for asthma inschoolchildren in southern Brazil. Jornal de Pediatria, Rio de Janeiro, v. 81, n. 5, p. 411-416, 2005.

CHONG-NETO, H. J. et al. Guia prático de abordagem da criança e do adolescente com asma grave: Documento conjunto da Associação Brasileira de Alergia e Imunologia e Sociedade Brasileira de Pediatria. Arquivos de Asma, Alergia e Imunologia, v. 4, n. 1, p. 3-34, 2020.

COLLET, C. et al. The First 1000 Days: Impact of prenatal tobacco smoke exposure on hospitalization due to preschool wheezing. Healthcare (Basel), v. 9, n. 8, 2021.

COOKSON, W. The alliance of genes and environment in asthma and allergy. Nature, v. 402, p. 5-11, 1999.

CRUZ, A. A. et al. Diretrizes da Sociedade Brasileira de Pneumologia e Tisiologia para o Manejo da Asma - 2012. Jornal Brasileiro de Pneumologia, v. 38, supl. 1, p.1-46, 2012.

EMERYK, A.; EMERYK-MAKSYMIUL, J. Short-acting inhaled $\beta 2$-agonists: why, whom, what, how? Advances in Respiratory Medicine, v. 88, n. 5, p. 443-449, 2020.

FERNANDES, S. S. C. et al. Epidemiological trends of allergic diseases in adolescents. Jornal Brasileiro de Pneumologia, v. 43, n. 5, p. 368-372, Sept./Oct. 2017.

FERREIRA, E. S. et. al. Novas terapias coadjuvantes ao tratamento clássico daasma

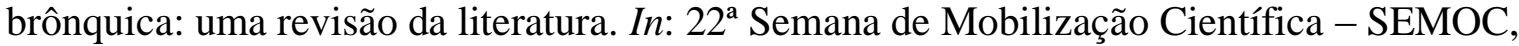
2019, Salvador. Anais [...], Salvador: Universidade Católica do Salvador 2019.

FIKS, I. N. Asma e exercício. Revista Brasileira de Crescimento e Desenvolvimento Humano, São Paulo, v. 18, n. 2, p. 209-213, ago. 2008.

FONTES, M. J. F. et al. Asma em menores de cinco anos: dificuldades nodiagnóstico e na prescrição da corticoterapia inalatória. Jornal Brasileiro de Pneumologia, São Paulo, v. 31, n. 3, p. 244-253, jun. 2005.

GINA - Global Initiative for Asthma. Global Strategy for Asthma Management and Prevention, 2018. Disponível em: https://ginasthma.org/wp-content/uploads/2018/04/wmsGINA-2018-report-V1.3-002.pdf. Acesso em: 20 jun. 2021.

GINA - Global Initiative for Asthma. Global Strategy for Asthma Management and Prevention, 2020. Disponível em: https://ginasthma.org/wp-content/uploads/2020/04/GINA2020-full-report_final-_wms.pdf. Acesso em: 20 jun. 2021.

GINA - Global Initiative for Asthma. Global Strategy for Asthma Management and Prevention, 2021. Disponível em: https://ginasthma.org/wp-content/uploads/2021/05/GINAMain-Report-2021-V2-WMS.pdf. Acesso em: 20 jun. 2021.

Revista Extensão \& Cidadania, v. 9, n. 16, p. 33-51, jul./dez. 2021.

ISSN 2319-0566 DOI: 10.22481/recuesb.v9i16.8679 
HOLGATE, S. T. The immunopharmacologyn of mild asthma. Journal of Allergy and ClinicalImmunology, v. 98, n. 5, p.7-16, nov. 1996.

KUWAKINO, M. S. et al. Doença do refluxo gastroesofágico e sua relação com a asma. Revista Brasileira de Alergia e Imunopatologia, v. 30, n. 1, p.13-20, 2007.

LANG, J.E.; TANG, M. Tabagismo: ainda é um grande problema em crianças com asma. Jornal de Pediatria, Rio de Janeiro, v. 95, n. 5, set./out. 2019.

LEWIS, S. et al. Study of the aetiology of wheezing illness at age 16 in two nationalBritish birth cohorts. Thorax, v. 51, n. 7, p. 670-676, 1996.

MARTINEZ, F. D. et al. Asthma and wheezing in the first six years of life. New England Journal of Medicine, v. 332, p.133-138, 1995.

MARTINS, M. A. Asma e refluxo gastroesofágico. Jornal Brasileiro de Pneumologia, v. 33 , n. 2, p. 11-12, 2007.

MAUAD, T. et al. Remodelamento brônquico na asma. Jornal Brasileiro de Pneumologia, v. 26, n. 2, p. 91-98, abr. 2000.

MORAES, L. S. et al. Risk factors associated with wheezing in infants. Jornal de Pediatria, Rio de Janeiro, v. 89, n. 6, p.559-566, nov./dez. 2013.

MOURA, J. A. R. de; CAMARGOS, P. A. M.; BLIC, J. de. Tratamento profilático da asma. Jornal de Pediatria, Rio de Janeiro, v.78, supl. 2, p. 141-150, dez. 2002.

NASCIMENTO-CARVALHO, C. M. Antibioticoterapia ambulatorial como fator de indução da resistência bacteriana: uma abordagem racional para as infecções de viasaéreas. Jornal de Pediatria, Rio de Janeiro, v. 82, n. 5, supl. p. 146-152, nov. 2006.

PEDERSEN, S. E. et al. Global strategy for the diagnosis and management of asthma in children 5 years and younger. Pediatric Pulmonology, v. 46, n. 1 p. 1-17, 2011.

PINTO, J. R.; SILVA, I. C. Programa Nacional para as Doenças Respiratórias. Manual para abordagem da sibilância e asma em idade pediátrica. Governo de Portugal: Ministério da Saúde, 2014.

PINTO, L. A.; STEIN, R. T.; RIBEIRO, J. D. Associação genética da asma e da sibilância induzida por vírus: uma revisão sistemática. Jornal Brasileiro de Pneumologia, v. 35, n. 12, 2009.

PINTO, L.; STEIN, R. T.; KABESCH, M. O impacto da genética na asma infantil. Jornal de Pediatria, Rio de Janeiro; Porto Alegre, v. 84, n. 4, supl., p. 68-75, ago. 2008.

PIZZICHINI, M. M. M. et al. Recomendações para o manejo da asma da Sociedade Brasileira de Pneumologia e Tisiologia - 2020. Jornal Brasileiro de Pneumologia, v. 46, n. 1, p. e20190307, 2020.

Revista Extensão \& Cidadania, v. 9, n. 16, p. 33-51, jul./dez. 2021. 
REIS, F. C. Asma: fatores de risco. Jornal de Pediatria, Rio de Janeiro, v. 73, p.151-160, 1997.

RIBEIRO, F. et al. Prescrição de antibióticos em um Departamento de Emergência Pediátrica de um hợdde nível II da Região Central. Nascer e Crescer - Jornal Médico de Nascimento e Crescimento, v. 22, n. 4, p. 216-219, 2013.

RISNES, K. R. et al. Antibiotic exposure by 6 months and asthma and allergy at 6 years: findings in a cohort of 1,401 us children. American Journal of Epidemiology, v. 173, n. 3, p. 310-318, Feb. 2011.

SANTANA, J. C. B.; MENNA BARRETO, S. S.; CARVALHO, P. R. A. Fatores associados com asma aguda grave na infância: aspectos epidemiológicos e clínicos. Jornal de Pediatria, Rio de Janeiro, v. 73, N. 5, p. 324-334, 1997.

SCALABRIN, D.M. et al. Efficacy and side effects of beta 2-agonists by inhaled route in acute asthma in children: comparison of salbutamol, terbutaline, and fenoterol. Journal of Asthma, v. 33, n. 6, p. 407-415, 1996.

SHEIKH, S. et al. Lung function in infants with wheezing and gastroesophageal reflux. Pediatric Pulmonology, v. 27, n. 4, p. 236-241, 1999.

SOLÉ, D. et al. A asma na criança: classificação e tratamento. Jornal de Pediatria, Rio de Janeiro, v. 74, Supl. 1, p. 48-58, 1998.

SOUSA, C. A. et al. Prevalência de asma e fatores associados: estudo de base populacional em São Paulo, SP, 2008-2009. Revista de Saúde Pública, v. 46, n. 5, p. 825-833, 2012.

SPORIK, R.; HOLGATE, S. T.; COGWELL, J. J. Natural history of asthma in childhood: a birth cohort study. Archives of Disease in Childhood, v. 66, n. 9, p. 1050-1053, Sept. 1991.

STIRBULOV, R.; BERND, L. A. G.; SOLÉ, D. IV Diretrizes Brasileiras no Manejo da ASMA. Revista Brasileira de Alergia e Imunopatologia, v. 29, n. 5, p. 222-245, 2006.

SUISSA S. et al. A cohort analysis of excess mortality in asthma and the use of inhaled betaagonists. American Journal of Respiratory and Critical Care Medicine, v. 149, n. 3, p. 604-610, 1994.

TABACHNIK, E.; LEVISON, H. Infantile bronchial asthma. Journal of Allergy and Clinical Immunology, v. 67, p. 339-347, 1981.

TEBET, E. N. Pesquisa de refluxo gastroesofágico através da phmetria intraesofágica de 24 horas em crianças asmáticas. Dissertação (Mestrado em Saúde da Criança e do Adolescente) - Universidade de São Paulo, Ribeirão Preto, 2000.

TEIXEIRA, B. C. et al. Refluxo gastroesofágico e asma na infância: um estudo de sua relação através de monitoramento do $\mathrm{pH}$ esofágico. Jornal de Pediatria, Rio de Janeiro; Porto Alegre, v. 83, n. 6, p. 535-540, dez. 2007.

Revista Extensão \& Cidadania, v. 9, n. 16, p. 33-51, jul./dez. 2021.

ISSN 2319-0566 DOI: 10.22481/recuesb.v9i16.8679 
TENROLLER, C. A. Asma e atividade física em crianças. Monografia (Especialização em Saúde Coletiva) - Universidade Luterana do Brasil, Canoas, 2004.

TRINCA, M. A.; BICUDO, I. M. P.; PELICIONI, M. C. F. A interferência da asma no cotidiano das crianças. Journal of Human Growth and Development, v. 21, n. 1, p. 70-84, 2011.

ULRIK, C. S. et al. Risk factors for development of asthma in children and adolescents: findings from a longitudinal population study. Respiratory Medicine, v. 90, n. 10, p. 623630, 1996.

VIEGAS, C. A. de A. Tabagismo e controle da asma brônquica. Jornal Brasileiro de Pneumologia, São Paulo, v. 35, n. 3, mar. 2009.

Recebido: 10.05.2021

Aceito: 04.08.2021

(c) (i)

This work is licensed under a Creative Commons Attribution 4.0 International License.

cc) (†)

Este trabalho está licenciado com uma Licença Creative Commons - Atribuição 4.0

Internacional.

Revista Extensão \& Cidadania, v. 9, n. 16, p. 33-51, jul./dez. 2021.

ISSN 2319-0566 DOI: 10.22481/recuesb.v9i16.8679 